\title{
Spatial and temporal variability in the responses of Arctic terrestrial ecosystems to environmental change
}

\author{
Terry V. Callaghan, Malcolm C. Press, John A. Lee, \\ David L. Robinson \& Clive W. Anderson
}

\begin{abstract}
This paper compares the responses of two contrasting Arctic ecosystems to climate change simulations: a polar semi-desert (in Svalbard) and a dwarf shrub heath (at Abisko, northern Sweden). These ecosystems are located close to the northern- and southernmost extremes of the Arctic region, respectively. Impacts of simulated climatic changes were determined through factorial perturbation experiments, where growing season temperature, nutrient availability and water supply were manipulated. The results are compared with the impact of interannual variation in climate on the growth of a keystone moss species, Hylocomium splendens, from the wider circumpolar area. The perturbation studies revealed that current interannual variability in temperature and the temperate tolerance of many species may exceed predicted changes in mean summer temperature over the next century. Arctic ecosystems differed in their responses to environmental manipulations, with the structure of the dwarf shrub heath being affected through shifts in competitive hierarchy, potentially leading to lower biodiversity, and the polar semi-desert being affected through invasion, potentially leading to higher diversity. $H$. splendens showed negative responses to perturbation at the sub-Arctic site, in contrast to the positive relationship between temperature and growth observed in the natural environment. This apparent discrepancy may result from: (i) artefacts arising from the perturbations, such as lower atmospheric relative humidity; (ii) non-equilibrium responses during the relatively short-term perturbation studies and/or (iii) ecotypic variation in the moss population. Thus, caution should be employed when extrapolating from perturbations studies to both longer time-scales and different ecosystems within the Arctic.
\end{abstract}

T. V. Callaghan. The Royal Swedish Academy of Sciences' Abisko Scientific Research Station, SE-98I 07 Abisko, Sweden, and the Sheffield Centre for Arctic Ecology, Dept. of Animal and Plant Sciences, Sheffield University, 26 Taptonville Road, Sheffield S10 5BR, UK; M. C. Press \& J. A. Lee, Dept. of Animal and Plant Sciences, Sheffield University, Alfred Denny Building, Western Bank, Sheffield S10 2TN, UK; D. L. Robinson \& C. W. Anderson, Dept. of Probability and Statistics, Sheffield University, Westem Bank, Sheffield S10 2TN, $U K$.

\section{Introduction}

Climate change is a global concern that is amplified in the Arctic since predicted increases in temperature are greater than for lower latitudes (Cattle \& Crossley 1995; Weller 1999). Permafrost, soils and biota are also likely to be particularly sensitive to change (Chapin, Jefferies et al. 1992). Plants, for example, have long life cycles with little possibility of adaptation, generally low and sporadically successful recruitment from sexual reproduction, and an existing burden of multiple stresses such as low nutrient availability, herbivory, and harsh climate (Jonasson et al. in press). Changes in Arctic ecosystems could have important consequences for the sustenance and cultural identity of northern human populations, the maintenance of a rich and characteristic wildlife, and the Earth's atmospheric circulation via albedo effects and by the sequestering of atmospheric $\mathrm{CO}_{2}$ in extensive organic soils. 
Although Global Circulation Models generally predict that the greatest warming will occur at high latitudes in the winter, it is clear that climatic changes will vary regionally. Indeed, recent changes have shown both cooling and warming in different areas of the Arctic: south and mid-west Greenland has cooled by $1{ }^{\circ} \mathrm{C}$ per decade whereas continental parts of Alaska and Siberia have warmed by the same extent over the past 30 years (Walsh, quoted in Weller in press). Other areas, such as Arctic Europe, have warmed only moderately, and then mainly during the present decade. It is therefore, dangerous to generalize future climatic trends for the whole circum-Arctic region. Moreover, ecosystems vary considerably in structure and function throughout the region: they vary from open forest tundra at the southern border of the Arctic to polar desert in the far north, and from shrub communities at the altitudinal tree line to fell field in the alpine zone. Communities vary along continental gradients from moss-dominated communities in oceanic areas to relict tundra steppe communities in interior Alaska and Siberia. And plant communities vary from productive closed and relatively tall vegetation of woody species to open communities dominated by cryptogams with low productivity. Such different Arctic ecosystems would be expected to respond differently to even the same change in climate.

Climate also varies greatly with time. Diel variations around mid-summer and mid-winter are less pronounced than at lower latitudes but the seasonal variation is dramatic, with a snowfree growing season that seldom exceeds three months (Weller in press). At the annual scale, weather conditions vary between years and the temperatures of some months (often in spring and autumn) may vary markedly. In addition, extreme events occur. It is likely that trends of ecosystem responses in time will not be linear or follow a smooth trend but are likely to be punctuated with stochastic extreme events that may reinforce trends of ecosystem change or even negate them.

This paper focuses on a comparison between the responses of two contrasting Arctic ecosystems to climate change simulations. These ecosystems are located close to the northernmost and southernmost extremes of the Arctic region. Transient responses of these ecosystems to simulated climatic changes will be compared with equilibrium responses of a keystone plant species to climate over a longer period of time and from the wider circumpolar area.

\section{Approaches}

Two basic approaches are combined in this study. One is to perturb ecosystems by simulating some of the components of predicted climate change. This approach has been applied to a closed dwarf shrub heath community in Abisko in sub-Arctic Swedish Lapland $\left(68^{\circ} 21^{\prime} \mathrm{N}, 18^{\circ} 49^{\prime} \mathrm{E}\right)$ and a high Arctic polar semi-desert community in Svalbard $\left(78^{\circ} 56^{\prime} \mathrm{N}, 11^{\circ} 50^{\prime} \mathrm{E}\right)$ in which only about $40 \%$ of the ground was covered by vegetation. Full site descriptions are given in Wookey et al. (1993). The components of predicted climate change that were manipulated are (1) summer air temperature, which was increased by between 2.7 (Abisko) and $3.5^{\circ} \mathrm{C}$ (Svalbard) using open top plastic chambers (see Wookey et al. 1993 and Parsons et al. 1994 for details); (2) increased nutrient availability $(10,10$ and $12.6 \mathrm{~g} \mathrm{~m}^{-2} \mathrm{yr}^{-1}$ of $\mathrm{N}, \mathrm{P}$ and $\mathrm{K}$, respectively, at the Lapland site, and 5.0, 5.0 and $6.3 \mathrm{~g} \mathrm{~m}^{-2} \mathrm{yr}^{1}$ of $\mathrm{N}, \mathrm{P}$ and $\mathrm{K}$, respectively, at the Svalbard site) to explore the possibility of increases in microbial activity induced by soil warming and nutrient release, in addition to increased atmospheric nitrogen deposition; (3) increased summer precipitation (50\% in both Lapland and Svalbard).

The experiments, still in progress, were established in 1991 and results presented here are for the first five years. While this approach allows direct simulations of climate change to be made, it also gives insights in to the various current environmental constraints on ecosystems because the manipulations can be performed independently of each other as well as factorially. Also, the controls of the experiment serve as useful monitoring plots for natural interannual weather variations (Henry \& Molau 1997). However, a constraint of the experimental approach is that the manipulations are confined to quite small plots $(1.5 \mathrm{~m} \times 1.5 \mathrm{~m})$ rather than landscapes, and changes that occur are detected in real time over relatively short periods.

The second approach discussed here is the retrospective analysis of plant growth (Callaghan, Carlsson \& Tyler 1989; Callaghan, Carlsson, Sonesson et al. 1997). Some widespread Arctic species are long-lived and past growth can be identified and measured. This allows statistical 
Fig. 1. Changes in cover of the most abundant higher plants and mosses and lichens at the polar semi-desert site (Svalbard) related to increased nutrient availability (data from Robinson et al. 1998).

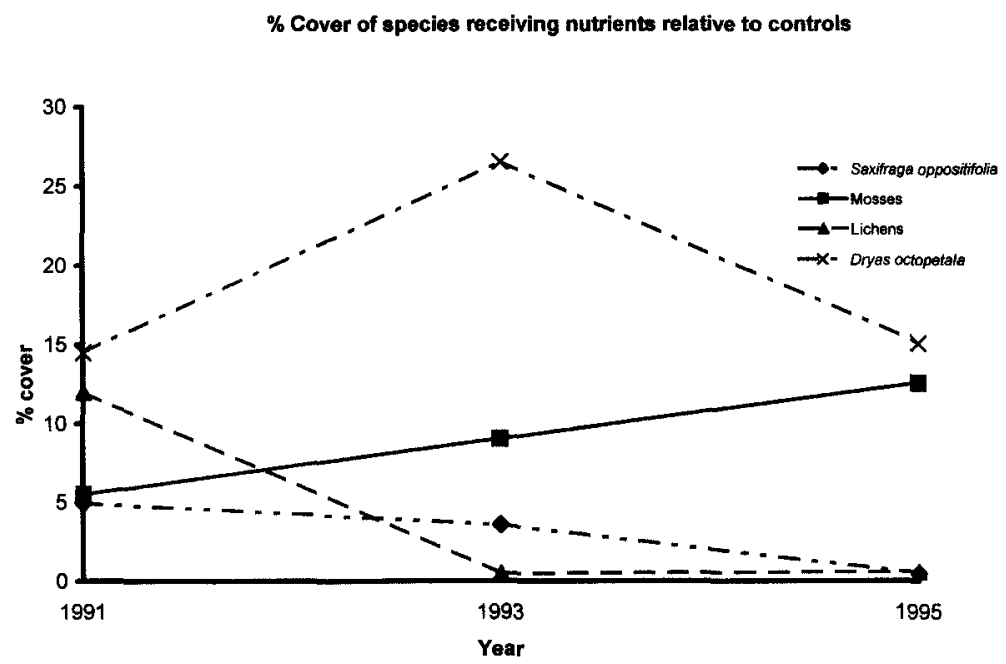

models to be constructed of climate-driven growth in ways analogous to dendrochronology (Callaghan, Carlsson \& Tyler 1989). Some species have records of growth that go back 30 years while even the moss Hylocomium splendens can contain growth records of more than 15 years (Callaghan, Carlsson, Sonesson et al. 1997). When samples are collected from different habitats, from different

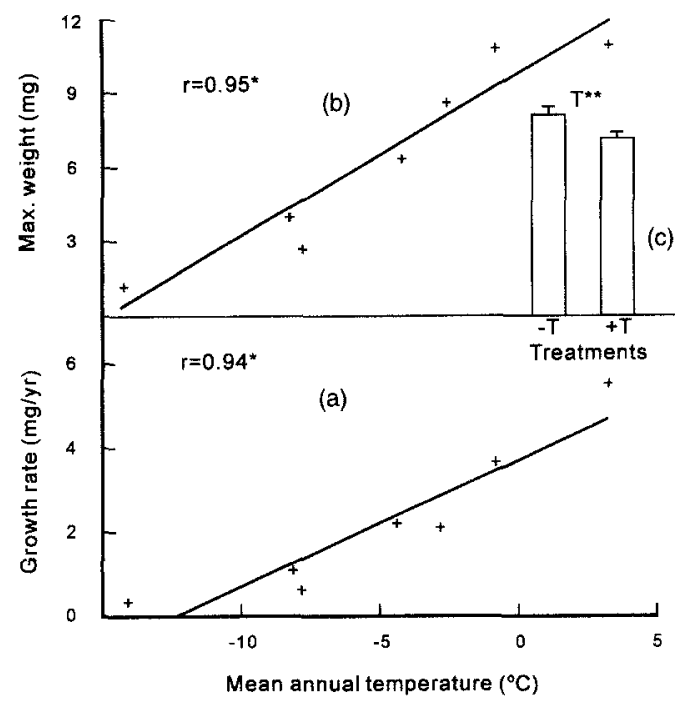

Fig. 2. (a) Growth rate and (b) maximum annual growth increment in Hylocomium splendens in relation to mean annual temperature at several Arctic sites (from Callaghan, Carlsson, Sonesson et al. 1997). (c) The effect of temperature elevation $(+T)$ on the dry wt. of the moss is also shown (from Potter et al. 1995). regions, or even from different historic periods, a greater understanding of plant responses to climate variation in space and time can be gained than with field manipulation experiments, although relationships between past growth and climate must remain correlative rather than causal. Together, the two approaches give a powerful insight into the complexity and probable causes of plant responses to climatic variations.

\section{Variation in space of Arctic ecosystems' responses to climate change}

(c) Responses of individual plant species to increased temperature were greater at the colder site, Svalbard, and were particularly pronounced in developmental processes such as flowering, reproductive development and leaf area expansion (Wookey et al. 1993). Enhanced seed production and viability in the open vegetation of the high Arctic is particularly important for the process of colonization and closure of vegetation cover (see below). Nutrient addition had fewer and smaller effects than increased temperature on reproductive development at the Svalbard site but stimulated vegetative growth, particularly of the dominant species Dryas octopetala and resulted initially in an increase in cover (Fig. 1) (Robinson 1997; Robinson et al. 1998). An increase in total plant cover, particularly in relation to nutrient addition, was also achieved by colonization of mosses and 
Assumptions

- There will be an increase of available nutrients similar to those given in the environmental manipulation experiment.

- No extreme weather event will occur.

- The spread of Dryas will be continuous and will occur at a maximal rate.

- There will be a linear increase in cover with time.

- There will be no competition from co-occurring or immigrating species.

- There will be no preferred directionality of growth.

Starting variables

Measured cover of Dryas at start

Available space (litter/organic detritus, dead plant parts and bare ground)

Maximum, measured annual rate of increase

immigrant higher plants, which had characteristics of nitrogen-rich bird cliff communities (Robinson et al. 1998).

At the sub-Arctic Abisko site, the four dominant dwarf shrubs showed individualistic responses to temperature increases (Parsons et al. 1994) but their responses to nutrient addition were even greater. The grass Calamagrostis lapponica increased its dominance at the Abisko site (Press et al. 1998) through an 18-fold increase in abundance and an increase in height that elevated the canopy by $86 \%$. Biomass at the site increased in relation to increased temperature and nutrients. Mosses at this site also showed individualistic responses to treatments: Hylocomium splendens showed reduced growth due to increased temperature or increased nutrients (Fig. 2) (Potter et al. 1995; Press et al. 1998), while Polytrichum commune increased its growth when nutrients were added.

Overall, therefore, the sites mainly differed in that increased nutrients and temperature led to an increased occupation of available space and an increased biodiversity at the polar semi-desert site. In contrast, these treatments led to an increase in height, change in dominance and a decrease in biodiversity at the sub-Arctic heath site where the canopy was already closed at the start of the experiments.

The increase in the cover of Dryas receiving nutrients and temperature enhancement between 1991 and 1993 suggests that under conditions of uniform warming, the sparse vegetation of the polar semi-desert community could close, with important implications for increased biomass and carbon storage. Making the assumptions outlined in Table 1, it is possible to calculate that Dryas could close its community within 12 years. However, many of these assumptions are unrealistic: nutrient availability is never likely to be as high as the experimental level; extreme weather events are likely to occur (see next section); an exponential increase in cover with time is more realistic than a linear trend; co-occurring and immigrant species may compete for space; and directionality of growth favours recolonization of dead matter, rather than bare ground, and extension along slopes (Robinson 1997).

When the actual rate of colonization of Dryas was modelled using observed patches of Dryas and rates of increase in cover measured for the experimental treatments, it was found that Dryas grew preferentially onto dead patches rather than onto bare ground (Robinson 1997). It also grew across a slope, rather than up or down (Figs. 3a, b), and over $80 \%$ of patches grew only $1 \mathrm{~cm}$ per year or less, with an exceptional maximum rate of radial growth of $4 \mathrm{~cm}$ per year (Fig. $3 \mathrm{c}$ ). Overall, the mean rate of growth was $0.86 \mathrm{~cm}$ per year.

\section{Variation in time of Arctic ecosystems' responses to climate change}

During a period of natural or experimental warming, the response of a given species occurs over a great range of time scales. These range from seconds, when photosynthesis responds to changing cloud conditions; through hours, when flowers track the sun's movements; through months, when seasonal changes in leaf develop- 


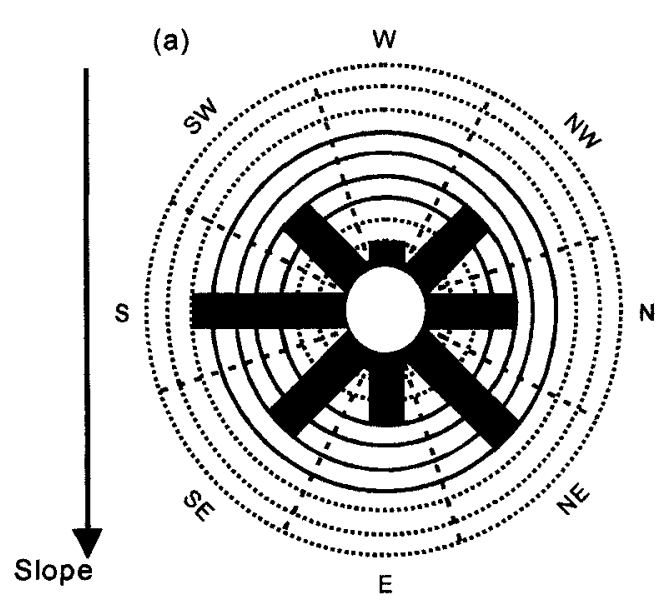

(b)

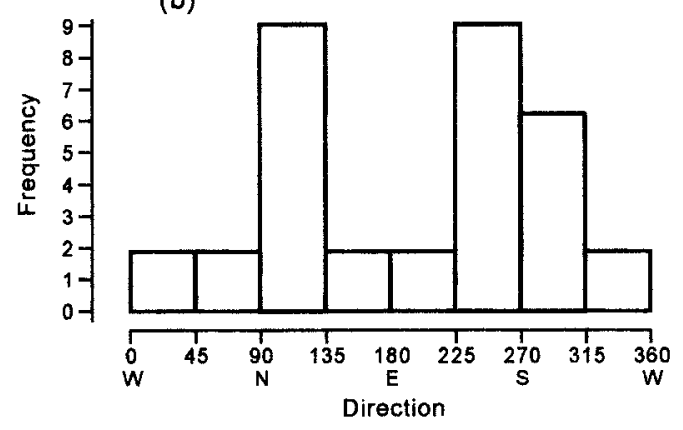

(c)

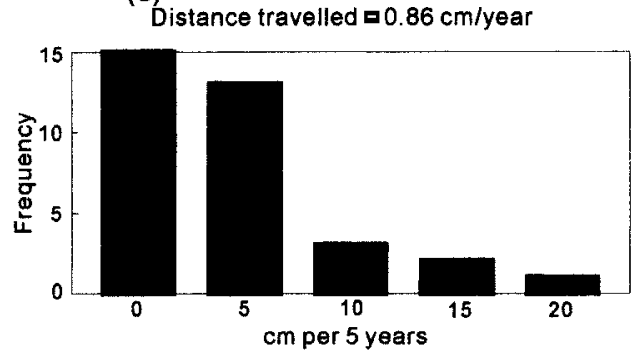

Fig. 3. (a) Circular histogram and (b) linear histogram showing directional growth and (c) rate of growth of Dryas octopetala clones from the polar semi-desert site in Svalbard (modified from Robinson 1997).

ment, reproduction and resource storage occur; to years, when life history parameters respond; and longer, when adaptation might occur. Although each of these processes has its own significance, it is changes in plant distribution and biodiversity that are particularly important integrative measures of response. Changes in productivity, while important in terms of ecosystem function, have a more limited range of response options.
Table 2. Characteristics of an extreme weather event and its impacts on the growth of Dryas octopetala at a polar semidesert site in Svalbard (from Robinson et al. 1998).

Weather characteristics

Precipitation (mm)

$\begin{array}{cc}\text { November weather } \\ \text { 1961-1996 mean } & 1993 \\ -7.0 & -2.8 \\ 69 & 230\end{array}$

Percent cover changes of living and dead Dryas with $(+\mathrm{F})$ and without $(-F)$ nutrient addition. $P$ is significance level for living and dead matter at $\mathrm{p} \leq 0.01^{* *}$ and $\mathrm{p} \leq 0.001^{* * *}$; ns is non-significant differences.

\begin{tabular}{lcccc} 
& & 1991 & 1993 & 1995 \\
Living matter & $+\mathrm{F}$ & 14.5 & 26.1 & 14.5 \\
Living matter & $-\mathrm{F}$ & 14.6 & 14.6 & 21.6 \\
$\mathrm{P}$ & & $\mathrm{ns}$ & $* * *$ & $\mathrm{~ns}$ \\
Dead matter & $+\mathrm{F}$ & 7.3 & 2.6 & 19.4 \\
Dead matter & $-\mathrm{F}$ & 8.9 & 4.2 & 11.3 \\
$\mathrm{P}$ & & $\mathrm{ns}$ & $\mathrm{ns}$ & $* *$ \\
\hline
\end{tabular}

During a period of warming, it is unlikely that ecosystems will reach an equilibrium stage or even keep pace with the changing environment. This applies particularly in the Arctic where plants are long-lived and many have specific mechanisms to buffer environmental changes such as interannual variations in weather (Callaghan, Carlsson \& Tyler 1989). Recorded responses of vegetation to experimental warming in the field must be seen, therefore, as a particular stage in a longer series of changes. Thus, in warming experiments in Alaska (Chapin, Shaver et al. 1995), alpine Lapland (Molau \& Alatalo 1998), and lowland Lapland (Jonasson 1992; Parsons et al. 1995; Press et al. 1998), ecosystem warming in the first year led to a change in dominance favouring graminoid species. However, after a decade or more in Alaska, dwarf birch increased its dominance. In the lowland heath at Abisko where polycormic mountain birch predominates, particularly vigorous, perhaps even monocormic trees typical of warmer areas, might be expected to become dominant eventually.

Natural warming may not follow such smooth trends in time, however. At the polar desert site in Svalbard, an exceptionally warm period occurred in November 1993 (Table 2). This was associated with exceptionally high precipitation that fell as rain rather than snow. The effect of this was to kill shoots of many species such as Dryas (Table 2), particularly those individuals that had received fertilizer addition and which remained green much later into autumn (Robinson et al. 1998). A result of this extreme event was that Dryas cover 
developed stochastically rather than smoothly over time (Fig. 1). Such extreme events can, theoretically, either enhance a longer trend of increasing vegetation cover in response to warming or, as seen here, negate it.

One problem associated with environmental manipulation experiments in the Arctic is that it is not feasible to sample all the variation existing within a given landscape or vegetation type, or to sample over a time period long enough for major community reorganizations to occur. As an example, environmental manipulation experiments in a lowland heath at Abisko in Lapland showed that mosses were particularly sensitive to manipulations. The moss Hylocomium splendens, which is particularly widespread and an important component of many northern ecosystems, showed a decrease in cover (Press et al. 1998) and vigour (Fig. 2; Potter et al. 1995) when temperature or nutrients were increased. This result contrasts with trends of increasing growth rate and size (maximum annual dry weight increment) with increasing temperature observed for populations collected from sites situated along a large annual temperature gradient (Fig. 2; Callaghan, Carlsson, Sonesson et al. 1997). Hylocomium is clearly found in areas warmer than those induced by the enhanced temperature treatment. Indeed, $H$. splendens is characteristic of some southern boreal forests with mean annual temperatures of about $7^{\circ} \mathrm{C}$ (Økland 1997) and some even warmer temperate regions.

Three possible mechanisms might explain this apparent discrepancy. First, experimental warming might have artefacts, such as reducing air moisture, that are particularly important for ectohydric mosses such as Hylocomium. However, natural increases in temperature without increases in precipitation might lead to a similar effect. Second, experimental warming over five years induced vegetation change only to the stage of dominance by graminoids and associations between this moss and dense grass canopies are not typical. Over a longer period, the stimulation of a denser forest canopy layer, either deciduous or evergreen coniferous, would be expected to reduce the dominance and density of the grasses below, cool the surface (Dyrness et al. 1986; Callaghan \& Jonasson 1995) and open up a new, characteristic niche for Hylocomium again. Alternatively, or in addition, warming at a much larger landscape scale would include far more niches available for a rearrangement of species associations such that species - like Hylocomium - might be lost from one association and niche, but could move into others. Such a suggestion was raised by Grime \& Callaghan (1988). They suggested that environmental factors producing patch effects such as aspect could play an important role in plant response to climatic warming. Thus, species characteristics of south facing slopes at the southern part of the species range, or local distributional limits, may be relocated to north-facing slopes while only species of north-facing slopes at the northern edge of their range would truly be under threat of loss. In the Arctic, small topographical gradients assume great significance for heat gain, soil moisture retention and other abiotic variables. Thus, warming may lead to species relocation over small distances under appropriate topographical conditions.

The mean annual temperature range naturally experienced by Hylocomium is considerable, even though the summer temperatures that the growing moss segments experience might show a smaller range. In the data illustrated in Fig. 2 it spans $16^{\circ} \mathrm{C}$; including Økland's populations (Økland 1997), the range exceeds $20^{\circ} \mathrm{C}$, from $-13^{\circ} \mathrm{C}$ to $+7^{\circ} \mathrm{C}$. This range is far greater than the expected increase in temperature over the next century, i.e. between 2 to $4^{\circ} \mathrm{C}$ in summer (Cattle \& Crossley 1995). Although there might be different ecotypes throughout this range, as a species, it is unlikely that Hylocomium will be displaced except from the southernmost areas of its distribution.

\section{Conclusions}

We still have limited ability to generalize about the impacts of environmental change on Arctic terrestrial ecosystems because of the spatial and temporal patterns of environmental change, the responses of ecosystems at various levels of complexity from physiological processes to ecosystem function and structure, and because of the complex interactions between co-occurring environmental change factors. However, the two approaches summarized here suggest that:

(i) Current interannual variability in summer temperature and the temperature tolerance of many circum-Arctic species might override predicted changes over the next century.

(ii) In closed communities, changes in nutrient availability will affect their structure through 
changes in competitive hierarchy, possibly leading to reduced biodiversity.

(iii) Major vegetation change in response to temperature is expected at high latitudes and altitudes, i.e. on substrates open to colonization and at the cold tolerance limit of the species. This should lead to increased biodiversity in these locations.

Acknowledgements. - We are grateful to the UK Natural Environment Research Council, which supported much of this work (grant GST/02/531), the EU-BASIS project (Framework IV, grant ENV4-CT-0637), staff at the Abisko Scientific Research Station, the Norwegian Polar Institute and the Kings Bay Kull Company for allowing us access to facilities, and past and present members of the Sheffield Centre for Arctic Ecology together with members of the Department of Plant Ecology, Lund University, for their past and present contributions to the research.

\section{References}

Callaghan, T. V., Carlsson, B. A., Sonesson, M. \& Temesvary, A. 1997: Between-year variation in climate-related growth of circumArctic populations of the moss Hylocomium splendens. Funct. Ecol. 11, 157-165.

Callaghan, T. V., Carlsson, B. A. \& Tyler, N. J. C. 1989: Historical records of climate related growth in Cassiope tetragona from the Arctic. $J$. Ecol. 77, 823-837.

Callaghan, T. V. \& Jonasson, S. 1995: Arctic terrestrial ecosystems and environmental change. Phil. Trans. $R$. Soc. Lond. A 352, 259-276.

Cattle, H. \& Crossley, J. 1995: Modelling Arctic climate change. Phil. Trans. R. Soc. Lond. A. 352, 201-213.

Chapin, F. S. III, Jefferies, R. S., Reynolds, G. R., Shaver, G. R. \& Svoboda, J. (eds.) 1992: Arctic ecosystems in a changing climate, an ecophysiological perspective. 469 pp. San Diego: Academic Press.

Chapin, F. S. III, Shaver, G. R., Giblin, A. E., Nadelhoffer, K. G. \& Laundre. J. A. 1995: Responses of Arctic tundra to experimental and observed changes in climate. Ecology 76 , 694-711.

Dyrness, C. T., Viereck, L. A. \& Van Cleve, K. 1986: Fire in taiga communities of interior Alaska. Ecol. Stud. 57, 74-86.

Grime, J. P. \& Callaghan, T. V. 1988: Direct and indirect effects of climate change on plant species, ecosystems and processes of conservation and amenity interest. (Contract Contract report ref. T07020b1). London: Dept. of the Environment (UK).

Henry, G. H. R. \& Molau, U. 1997: Tundra plants and climate change: the International Tundra Experiment (ITEX). Global Change Biol. 3 (suppl. 1), 1-9.

Jonasson, S. 1992: Growth responses to fertilization and species removal in tundra related to community structure and clonality. Oikos $63,420-429$.

Jonasson, S., Callaghan, T. V., Shaver, G. R. \& Nielsen, L. A. in press: Arctic terrestrial ecosystems and ecosystem function. In M. Nutall. \& T. V. Callaghan (eds.): The Arctic: its environment, peoples and policy. Reading: Harwood Academic Publishers.

Molau, U. \& Alatalo, J. M. 1998: Responses of subArctic-alpine plant communities to simulated environmental change: biodiversity of bryophytes, lichens and vascular plants. Ambio 27, 322-329.

Økland. R. H. 1997: Population biology of the clonal moss Hylocomium splendens in Norwegian boreal spruce forests. III. Six-year demographic variation in two areas. Lindbergia $22,49-68$.

Parsons, A. N., Welker, J. M., Wookey, P. A., Press, M. C., Callaghan, T. V. \& Lee, J. A. 1994: Growth responses of four sub-Arctic dwarf shrubs to simulated environmental change. J. Ecol. 82, 307-318.

Potter, J. A.. Press, M. C., Callaghan, T. V. \& Lee, J. A. 1995: Growth responses of Polytrichum commune Hedw. and Hylocomium splendens (Hedw.) Br. Eur. to simulated environmental change. New Phytol. 131, 533-541.

Press, M. C., Potter, J. A., Burke, M. J. W., Callaghan, T. V. \& Lee, J. A. 1998: Response of a sub-Arctic dwarf shrub heath community to simulated environmental change. J. Ecol. 86 , 315-327.

Robinson, C. H., Wookey, P. A., Lee, J. A., Callaghan, T. V. \& Press, M. C. 1998: Plant community responses to simulated environmental change at a high Arctic polar semi-desert. Ecology 79, 856-866.

Robinson, D. 1997: Directional preferences in Arctic plant movement. M.Sc. thesis, University of Sheffield, UK.

Weller, G. in press: The climate of the Arctic. In M. Nutall \& T. V. Callaghan (eds.): The Arctic: its environment, peoples and policy. Reading: Harwood Academic Publishers.

Wookey, P., Parsons, A., Welker, J. M., Potter, J., Callaghan, T. V., Lee, J. A. \& Press, M. C. 1993: Comparative responses of phenology and reproductive development to simulated environmental change in sub-Arctic and high Arctic plants. Oikos 67, 490-502. 